\title{
Factors for short-term outcomes in patients with a minor stroke: results from China National Stroke Registry
}

Lingyun $\mathrm{Wu}^{1 \dagger}$, Anxin Wang ${ }^{2,3,4,5,6 \dagger}$, Xianwei Wang ${ }^{2,3,4,5}$, Xingquan Zhao 2,3,4,5 , Chunxue Wang ${ }^{2,3,4,5}$, Liping Liu Li, $^{2,4,5}$, Huaguang Zheng ${ }^{2,3,4,5}$, Yongjun Wang ${ }^{2,3,4,5}$, Yibin Cao ${ }^{7^{*}}$, Yilong Wang ${ }^{2,3,4,5^{*}}$ and on behalf of the China National Stroke Registry investigators

\begin{abstract}
Background: Stroke recurrence and disability in patients with a minor stroke is one of the most depressing medical situations. In this study, we aimed to identify which factors were associated with adverse outcomes of a minor stroke.

Methods: The China National Stroke Registry (CNSR) is a nationwide prospective registry for patients presented to hospitals with acute cerebrovascular events between September 2007 and August 2008. The 3-month follow-up was completed in 4669 patients with a minor stroke defined as the initial neurological severity lower than 4 in the National Institutes of Health Stroke Scale (NIHSS). Multivariate model was used to determine the association between risk factors and clinical outcomes.

Results: Of 4669 patients with a minor stroke during 3-month follow-up, 459 (9.8 \%) patients experienced recurrent stroke, 679 (14.5\%) had stroke disability and 168 (3.6\%) died. Multivariate model identified hypertension, diabetes mellitus, atrial fibrillation, coronary heart disease and previous stroke as independent predictors for the recurrent stroke. Age, diabetes mellitus, atrial fibrillation, previous stroke and time from onset to admission $<24 \mathrm{~h}$ were independent predictors for stroke disability. The independent predictors for the all-caused death were age, atrial fibrillation, and coronary heart disease.
\end{abstract}

Conclusions: The short-term risk of poor clinical outcome in Chinese patients with a minor stroke was substantial. Therefore, patients with a minor stroke should be given expeditious assessment and urgent aggressive intervention.

Keywords: Minor stroke, Risk factors, Stroke recurrence, Poor functional outcome

\section{Background}

Stroke recurrence and dependency in patients with an initial non-disabling stroke is one of the most depressing medical situations worldwide. Stroke has been the leading cause of death and acquired adult disability in China $[1,2]$, furthermore, where the incidence rate of ischemic stroke increased by $8.7 \%$ annually on average from 1984 to 2004 [3]. Increasing evidences have suggested that a

\footnotetext{
* Correspondence: yibin07@sina.com; yilong528@gmail.com

${ }^{\dagger}$ Equal contributors

${ }^{7}$ Department of Neurology, Tangshan Gongren Hospital, Tangshan, China

2Department of Neurology, Beijing Tiantan Hospital, Capital Medical

University, Beijing, China

Full list of author information is available at the end of the article
}

significant minority of patients with an acute nondisabling stroke become disabled or dead due to recurrent strokes or neurological deterioration within first few hours or days [4-6]. A population-based study showed that the true risk of recurrent stroke after minor stroke is up to about $18 \%$ at 3 months [7]. As for stroke-related disability, it is relatively common among the patients with mild or rapid improving symptom who were not treated with the intravenous thrombolysis $[5,6,8,9]$.

Considering the variable clinical course in the immediate aftermath of a minor stroke, it will become more important to assess risk factors for detecting patients with a poorer clinical outcome, for whom aggressive

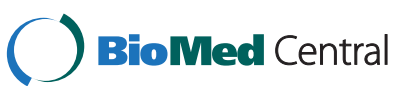

(c) 2015 Wu et al. Open Access This article is distributed under the terms of the Creative Commons Attribution 4.0 International License (http://creativecommons.org/licenses/by/4.0/), which permits unrestricted use, distribution, and reproduction in any medium, provided you give appropriate credit to the original author(s) and the source, provide a link to the Creative Commons license, and indicate if changes were made. The Creative Commons Public Domain Dedication waiver (http://creativecommons.org/publicdomain/zero/1.0/) applies to the data made available in this article, unless otherwise stated. 
prevention treatment like dual or triple antiplatelet is urgently needed. At present, majority of studies have been focusing on the early risk of recurrent stroke after transient ischemic attack (TIA) and a minor stroke [10-13], but data about the short-term risk of poor functional outcome and subsequent stroke assessed in patients with minor stroke was limited, and even not available in China. Using China National Stroke Registry (CNSR), we aimed to identify factors associated with early stroke recurrence, stroke disability and all-cause death after an initial minor stroke during a 90-day follow-up period.

\section{Methods}

\section{Study population}

The present cohort was from the China National Stroke Registry (CNSR), which is a nationwide prospective registry for patients presented to hospitals with acute cerebrovascular events between September 2007 and August 2008. The detailed design, rationale, and basic description of the CNSR have been published previously $[14,15]$. We included patients in the current analysis if they presented with an ischemic stroke diagnosed according to World Health Organization criteria [16, 17] combined with the confirmation of brain computed tomography or magnetic resonance imaging. The minor stroke was defined as the initial neurological severity lower than 4 in the National Institutes of Health Stroke Scale (NIHSS) $[17,18]$. We excluded the patients without follow-up information at 3 months after stroke onset. The study was sponsored by the Ministry of Science and Technology and the Ministry of Health of the People's Republic of China and approved by the central institutional review board at Beijing Tiantan Hospital and local ethical committees at each participating hospital. Written informed consent for inclusion was signed by patients or legally authorized representatives.

\section{Data collection}

All research coordinators and study investigators were trained and certified to assess National Institutes of Health Stroke Scale scores before the beginning of the study. We collected baseline information including patient demographics, vascular risk factors, stroke severity (NIHSS score at admission and $24 \mathrm{~h}$ later), stroke management, diagnosis and discharge status. Vascular risk factors included hypertension, diabetes mellitus, dyslipidemia, atrial fibrillation, coronary heart disease, previous stroke, current or previous smoking and moderate or heavy alcohol consumption ( $\geq 2$ standard alcohol consumption per day) and body mass index (BMI) at admission. Hypertension was defined as systolic blood pressure $\geq 140 \mathrm{mmHg}$ or diastolic blood pressure $\geq 90 \mathrm{mmHg}$, any use of antihypertensive drug, or self-reported history of hypertension. Diabetes mellitus was defined as fasting glucose level $\geq 7.0 \mathrm{mmol} / \mathrm{L}$, non-fasting glucose concentration $\geq 11.1 \mathrm{mmol} / \mathrm{L}$, any use of glucose-lowering drugs, or any self-reported history of diabetes. Dyslipidemia was defined as serum triglyceride $\geq 1.7 \mathrm{mmol} / \mathrm{L}$, low-density lipoprotein cholesterol $\geq 3.6 \mathrm{mmol} / \mathrm{L}$, high-density lipoprotein cholesterol $\leq 1.0 \mathrm{mmol} / \mathrm{L}$, any use of lipid-lowering drugs, or any self-reported history of dyslipidemia. Atrial fibrillation was defined as history of atrial fibrillation confirmed by at least one electrocardiogram or presence of the arrhythmia during hospitalization. The treatment of atrial fibrillation defined the use of anticoagulation agents during hospitalization and after discharge. BMI was calculated by dividing measured weight in kilograms by the square of measured height in meters. In addition, neurological deterioration was considered as the increase of NIHSS $\geq 4$ at $24 \mathrm{~h}$ after admission from baseline [19]. Etiologic subtypes of ischemic stroke were classified by the Stop Stroke Study Trial of Org 10172 in Acute Stroke Treatment (SSS-TOAST) classification criteria [20].

\section{Outcome assessment}

The follow up was done by telephone interview. Trained research personnel making the phone calls were blinded to patients' baseline clinical status. Patients were asked the standardized follow-up questions at 3 months after stroke onset. Outcomes data collected included stroke recurrence, stroke disability and all-cause death. Recurrent cerebrovascular events included ischemic stroke, intracranial hemorrhage and subarachnoid hemorrhage. Cases of recurrent strokes were cross-checked with the treating hospitals to ensure the accuracy of diagnosis. In case of a suspected stroke recurrence without hospitalization, the case was adjudicated by the trial executive committee. Stroke disability was defined as modified Rankin Scale (mRS) of 3-6 at 3 months after stroke onset. All-cause mortality was defined as death from any cause which was confirmed by either a death certificate from the local citizen registry or the record of the treating hospital. When no official documentation was available, case fatality was decided if death was reported on two consecutive followup periods by different proxies.

\section{Statistical analysis}

Continuous variables are expressed as means with standard deviation (SD) or median with interquartile range (IQR), as appropriate. Categorical data are presented as proportions. The differences in baseline demographic and clinical features between patients with poor clinical outcomes (early recurrent stroke, stroke disability and all-cause death) and those without poor clinical outcomes at 3 months after minor stroke were tested for continuous variables with normal distribution using 
one-way analysis of variance and continuous variables with skewed distribution using Kruskal-Wallis test. The $\mathrm{x} 2$ or Fisher exact test was used for categorical variables.

We analyzed the association between the clinical outcomes including early recurrent stroke, stroke disability and all-cause death and relevant covariates with logistic regression analysis adjusting age, gender, hypertension, diabetes mellitus, dyslipidemia, atrial fibrillation, coronary heart disease, previous stroke, current or previous smoking, moderate or heavy alcohol, BMI at admission, and admission within $24 \mathrm{~h}$ or not after stroke onset.

We have determined that two-tailed $\mathrm{p}$ values less than 0.05 was statistically significant. All statistical analyses were carried out with SAS Version 9.4 software. (SAS Institute Inc., U.S.)

\section{Results}

\section{Patient recruitments}

Of the 22,216 patients enrolled in the CNSR, 18,580 patients had complete baseline information and agreed to participate in the 90-day follow-up. Among them, 855 patients were excluded due to loss to follow-up at 3 months. After excluding 6891 patients with an initial NIHSS $\geq 4$, a total of 4669 patients with minor stroke (the initial NIHSS $<4$ ) were remained finally (Fig. 1).

Univariate analysis of patients with or without recurrent stroke, stroke disability and all-cause death at 3 months after minor stroke

Of 4669 patients with a minor stroke during 90-day follow-up, 459 (9.8 \%) patients experienced recurrent stroke, 679 (14.5\%) had stroke disability and 168 (3.6 \%) died. (Tables 1, 2 and 3) Of 168 patients who died, 77 $(45.8 \%)$ died of recurrent stroke. In univariate analysis, patients with stroke recurrence at 3 months after minor stroke had a higher rate of hypertension, diabetes mellitus, dyslipidemia, atrial fibrillation, coronary heart disease, previous stroke, time from onset to admission $<24 \mathrm{~h}$, neurological deterioration and large-artery atherosclerosis/ cardioembolism subtype of toast type than those without recurrence. Patients with recurrence stroke were more likely to be older and have a higher median NIHSS score at admission than those without recurrence. There was no difference between patients with recurrence stroke and those without recurrence stroke in gender, current or previous smoking, moderate or heavy alcohol, treated atrial fibrillation, median BMI at admission and median NIHSS score at $24 \mathrm{~h}$ (Table 1 ).

Table 2 showed older and female patients were more likely to be dependency at 3 months after minor stroke $(P<0.05)$. Patients with dependency were significantly more likely to have hypertension, diabetes mellitus, atrial fibrillation, coronary heart disease, previous stroke, current or previous smoking, moderate or heavy alcohol, time from onset to arriving at hospital $<24 \mathrm{~h}$, neurological deterioration and large-artery atherosclerosis/cardioembolism subtype of toast type, as compared with those without dependency. Finally, patients with dependency had a higher median BMI at admission and median NIHSS score at $24 \mathrm{~h}$ than those without recurrence. There was no statistically significant difference between the patients with dependency and those without dependency in

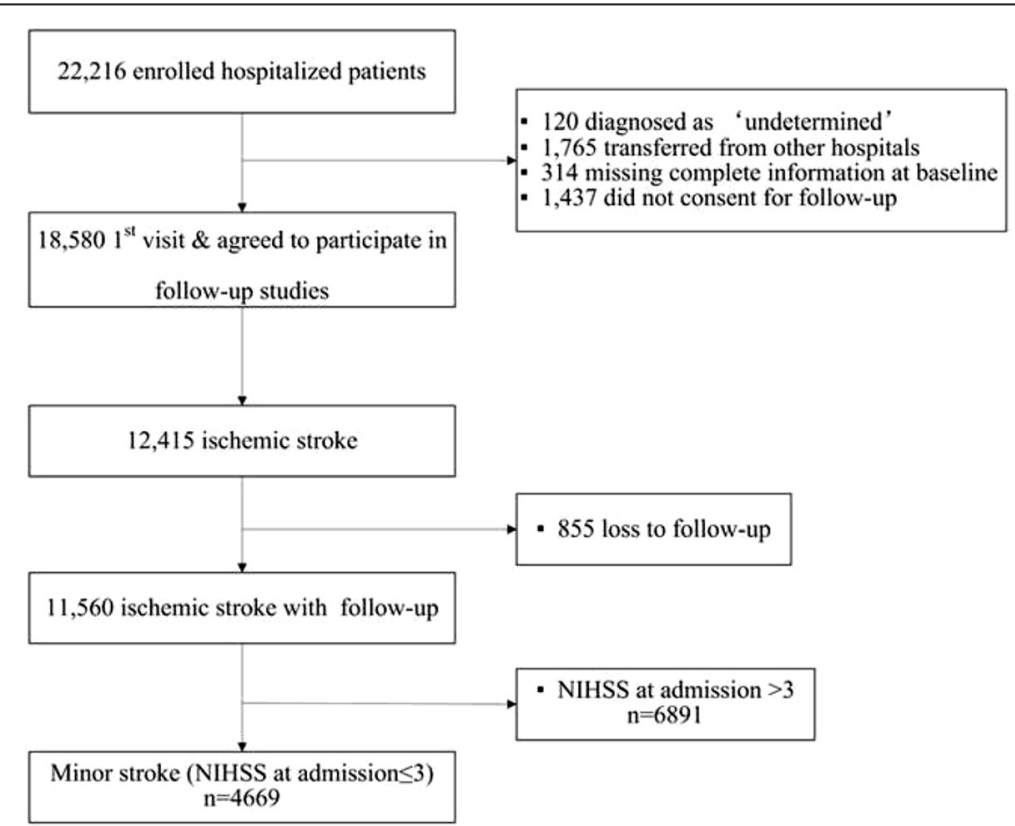

Fig. 1 Flow chart showing the patient selection. NIHSS, National Institutes of Health Stroke Scale 
Table 1 Univariate analysis of patients with or without stroke recurrence at 3 months after minor stroke

\begin{tabular}{|c|c|c|c|c|}
\hline Variables & Overall & Recurrence & No recurrence & $P$ value \\
\hline Sample size, n (\%) & 4669 & $459(9.8)$ & $4210(90.2)$ & \\
\hline Age, median (IQR), year & $65(55-74)$ & $67(57-76)$ & $65(55-73)$ & $<0.001$ \\
\hline Female, n (\%) & $1656(35.5)$ & 159 (34.6) & 1497 (35.6) & 0.70 \\
\hline \multicolumn{5}{|l|}{ Vascular risk factors } \\
\hline Hypertension, n (\%) & $3438(73.6)$ & $365(79.5)$ & $3073(73.0)$ & 0.003 \\
\hline Diabetes mellitus, n (\%) & $1274(27.3)$ & $148(32.2)$ & $1126(26.8)$ & 0.01 \\
\hline Dyslipidemia, n (\%) & $550(11.8)$ & $68(14.8)$ & $482(11.4)$ & 0.03 \\
\hline Atrial fibrillation, n (\%) & $270(5.8)$ & $53(11.6)$ & $217(5.2)$ & $<0.001$ \\
\hline Treated atrial fibrillation, n (\%) & $29(10.7)$ & $4(7.5)$ & $25(11.5)$ & 0.55 \\
\hline Coronary heart disease, n (\%) & $600(12.8)$ & $90(19.6)$ & $510(12.1)$ & $<0.001$ \\
\hline Previous stroke, n (\%) & $1451(31.1)$ & $196(42.7)$ & $1255(29.8)$ & $<0.001$ \\
\hline Current or previous smoking, n (\%) & $1872(40.1)$ & $178(38.8)$ & $1694(40.2)$ & 0.54 \\
\hline Moderate or heavy alcohol, n (\%) & $470(10.1)$ & $47(10.2)$ & $423(10.0)$ & 0.90 \\
\hline BMI at admission, median (IQR), $\mathrm{kg} / \mathrm{m}^{2}$ & $24.22(22.3-26.3)$ & $24.22(22.4-26.6)$ & $24.22(22.3-26.3)$ & 0.41 \\
\hline \multicolumn{5}{|l|}{ NIHSS score, median (IQR) } \\
\hline At admission & $2(1-3)$ & $1(0-2)$ & $2(1-3)$ & 0.001 \\
\hline At $24 \mathrm{~h}$ & $2(1-3)$ & $2(1-3)$ & $2(1-3)$ & 0.74 \\
\hline Time from onset to admission $<24 \mathrm{~h}, \mathrm{n}(\%)$ & $2472(52.9)$ & $263(57.3)$ & $2209(52.5)$ & 0.049 \\
\hline Neurological deterioration, n (\%) & $166(3.6)$ & $31(6.8)$ & $135(3.2)$ & $<0.001$ \\
\hline TOAST subtype, $\mathrm{n}(\%)$ & & & & $<0.001$ \\
\hline Large-artery atherosclerosis & $1951(41.8)$ & $208(45.3)$ & $1743(41.4)$ & \\
\hline Small-artery occlusion & $1066(22.8)$ & $84(18.3)$ & $982(23.3)$ & \\
\hline Cardioembolism & $131(2.8)$ & $28(6.1)$ & $103(2.4)$ & \\
\hline Other & $176(3.8)$ & $13(2.8)$ & $163(3.9)$ & \\
\hline
\end{tabular}

IQR interquartile range, NIHSS National Institutes of Health Stroke Scale, BMI body mass index, TOAST Trial of Org 10172 in Acute Stroke Treatment

the following factors: dyslipidemia and median NIHSS score at admission.

Factors associated with all-cause death in patients after minor stroke are showed in Table 3. In the univariate analysis, the variables associated with death include age, atrial fibrillation, coronary heart disease, previous stroke, median BMI and NIHSS score, neurological deterioration and TOAST subtype (all $P$ value $<0.05$ ).

\section{Predictors of outcomes}

Figure 2 showed adjusted odds ratios (OR) and $95 \%$ confidence internals (CI) of the risk factors for stroke recurrence, stroke disability and all-caused death at 3 months in patients with the minor stroke using the multivariable logistic regression analysis. We identified the hypertension, diabetes mellitus, atrial fibrillation, coronary heart disease and previous stroke as independent predictors for recurrent stroke at 3 months after stroke onset. The independent predictors for the stroke disability at 3 months were age, diabetes mellitus, atrial fibrillation, previous stroke and time from onset to admission $<24 \mathrm{~h}$. Age, atrial fibrillation and coronary heart disease were independently associated with the all-caused death at 3 months after stroke onset.

\section{Discussion}

In the largest sample of Chinese stroke adults to date, the present study found that a significant minority of patients with the minor stroke experienced permanent neurological deficits or death and the recurrent stroke during the 3-month follow-up period. Nevertheless, patients at earlier phase after minor stroke were more likely to have high risk of stroke recurrence and poor functional outcome at 3 months after stroke onset.

Our data showed a 3-month recurrence rate of $9.8 \%$ in patients with a minor stroke. The short-term risk of stroke recurrence was consistent to about $10 \%$ at 3 months after TIA $[10,11]$, but lower than the range between 14 and $18 \%$ found in two previous studies of patients with a minor stroke $[7,21]$. The early risk of sequent stroke is commonly underestimated with the reason that patients were usually enrolled several days after a minor stroke and any patient who had a major stroke before the recruitment was not included. We also 
Table 2 Univariate analysis of patients with or without stroke disability at 3 months after minor stroke

\begin{tabular}{|c|c|c|c|c|}
\hline Variables & Overall & Disability & No disability & $P$ value \\
\hline Sample size, n (\%) & 4669 & $679(14.5)$ & $3990(85.5)$ & \\
\hline Age, median (IQR), year & $65(55-74)$ & $72(62-78)$ & $64(55-72)$ & $<0.001$ \\
\hline Female, n (\%) & $1656(35.5)$ & $281(41.4)$ & $1375(34.5)$ & $<0.001$ \\
\hline \multicolumn{5}{|l|}{ Vascular risk factors } \\
\hline Hypertension, n (\%) & $3438(73.6)$ & $527(77.6)$ & $2911(73.0)$ & 0.01 \\
\hline Diabetes mellitus, n (\%) & $1274(27.3)$ & $251(37.0)$ & $1023(25.6)$ & $<0.001$ \\
\hline Dyslipidemia, n (\%) & $550(11.8)$ & $79(11.6)$ & $471(11.8)$ & 0.90 \\
\hline Atrial fibrillation, n (\%) & $270(5.8)$ & $75(11.0)$ & $195(4.9)$ & $<0.001$ \\
\hline Coronary heart disease, n (\%) & $600(12.8)$ & $124(18.3)$ & $476(11.9)$ & $<0.001$ \\
\hline Previous stroke, n (\%) & $1451(31.1)$ & $273(40.2)$ & $1178(29.5)$ & $<0.001$ \\
\hline Current or previous smoking, n (\%) & $1872(40.1)$ & $229(33.7)$ & $1643(41.2)$ & $<0.001$ \\
\hline Moderate or heavy alcohol, n (\%) & $470(10.1)$ & $39(5.7)$ & $431(10.8)$ & $<0.001$ \\
\hline $\mathrm{BMI}$ at admission, median (IQR), kg/m2 & $24.22(22.3-26.3)$ & $24.03(22.0-26.0)$ & $24.22(22.5-26.4)$ & 0.03 \\
\hline \multicolumn{5}{|l|}{ NIHSS score, median (IQR) } \\
\hline At admission & $2(1-3)$ & $2(0-3)$ & $2(1-3)$ & 0.06 \\
\hline At $24 \mathrm{~h}$ & $2(1-3)$ & $3(2-3)$ & $2(1-3)$ & $<0.001$ \\
\hline Time from onset to admission $<24 \mathrm{~h}, \mathrm{n}(\%)$ & $2472(52.9)$ & $1641(54.5)$ & $831(50.2)$ & 0.005 \\
\hline Neurological deterioration, n (\%) & $166(3.6)$ & $270(39.8)$ & $1927(48.3)$ & $<0.001$ \\
\hline TOAST subtype, $\mathrm{n}(\%)$ & & & & $<0.001$ \\
\hline Large-artery atherosclerosis & $1951(41.8)$ & $303(44.6)$ & $1648(41.3)$ & \\
\hline Small-artery occlusion & $1066(22.8)$ & $94(13.8)$ & $972(24.4)$ & \\
\hline Cardioembolism & $131(2.8)$ & $44(6.5)$ & $87(2.2)$ & \\
\hline Other & $176(3.8)$ & $21(3.1)$ & $155(3.9)$ & \\
\hline
\end{tabular}

Stroke disability was defined as modified Rankin Scale $>2$; IQR interquartile range, BMI body mass index, NIHSS National Institutes of Health Stroke Scale, TOAST Trial of Org 10172 in Acute Stroke Treatment

detected that hypertension, diabetes mellitus and previous stroke were predictors of early recurrent stroke, as was suggested in previous studies $[10,11]$. Atrial fibrillation was independently associated with the risk of early recurrent stroke, which was not confirmed in population from western countries $[11,21]$. The possible explanation is that in clinical practice of China, unlike North America and Europe, only $14.3 \%$ stroke patients with atrial fibrillation receive oral anticoagulation in real clinical practice [22]. Of those patients who developed recurrent stroke in our study, $7.5 \%$ patients with atrial fibrillation received anticoagulation, which was lower than the early study. Previous studies had reported that coronary artery disease was strongly associated with stroke [23, 24]. Carotid atherosclerosis and stroke of carotid origin are coronary artery disease risk equivalents [25], thus coronary artery disease and cerebrovascular diseases are highly correlated. Our present study found that coronary artery disease was significantly associated with the risk of stroke recurrence at 3 months after adjusting other risk factors, so coronary artery disease can be regarded as an independent risk factor. The impact of time after a minor stroke for stroke recurrence was also dissected out in multivariate model analysis. It presented that the patients at the earlier phase of minor stroke were more likely to experience subsequent stroke (OR 1.22; 95 \% CI, 0.99-1.51; $p=0.06$ ).

The clinical functional outcomes of patients with minor stroke is not invariably benign. The rate of patients with stroke disability at 3 months in this study was up to $14.5 \%$. The multivariable-adjusted analysis revealed that patients at earlier phase of minor stroke $(\leq 24 \mathrm{~h})$ were about 1.5 times more likely to have a stroke disability at 3 months, and tended to have all-cause death at 3 months. The reason was unknown, but it was reported in a previous study [26] that patients with more severe stroke immediately contacted emergency services after stroke onset to avoid disability and death. Therefore, it's likely that the time from onset to admission was a proxy for stroke severity even in minor strokes.

The study had some limitations. First, the participating hospitals were selected by convenience in nature. The majority of hospitals selected were tertiary hospitals that may not represent the status quo of stroke in rural and 
Table 3 Univariate analysis of patients with or without all-cause death at 3 months after minor stroke

\begin{tabular}{|c|c|c|c|c|}
\hline Variables & Overall & Death & No death & $P$ value \\
\hline Sample size, n (\%) & 4669 & 168 (3.6) & $4501(96.4)$ & \\
\hline Age, median (IQR), year & $65(55-74)$ & $72(60-77)$ & $65(55-73)$ & $<0.001$ \\
\hline Female, n (\%) & $1656(35.5)$ & $70(41.7)$ & $1586(35.2)$ & 0.87 \\
\hline \multicolumn{5}{|l|}{ Vascular risk factors } \\
\hline Hypertension, n (\%) & $3438(73.6)$ & $122(72.6)$ & $3316(73.7)$ & 0.76 \\
\hline Diabetes mellitus, n (\%) & $1274(27.3)$ & $46(27.4)$ & $1228(27.3)$ & 0.98 \\
\hline Dyslipidemia, n (\%) & $550(11.8)$ & $21(12.5)$ & $529(11.8)$ & 0.77 \\
\hline Atrial fibrillation, n (\%) & $270(5.8)$ & $25(14.9)$ & $245(5.4)$ & $<0.001$ \\
\hline Coronary heart disease, n (\%) & $600(12.9)$ & $40(23.8)$ & $560(12.4)$ & $<0.001$ \\
\hline Previous stroke, n (\%) & $1451(31.1)$ & $68(40.5)$ & $1383(30.7)$ & 0.007 \\
\hline Current or previous smoking, n (\%) & $1872(40.1)$ & $62(36.9)$ & $1810(40.2)$ & 0.39 \\
\hline Moderate or heavy alcohol, n (\%) & $470(10.1)$ & $11(6.6)$ & $459(10.2)$ & 0.12 \\
\hline $\mathrm{BMI}$ at admission, median (IQR), kg/m2 & $24.22(22.3-26.3)$ & $23.61(21.7-26.0)$ & $24.22(22.4-26.3)$ & $<0.001$ \\
\hline \multicolumn{5}{|l|}{ NIHSS score, median (IQR) } \\
\hline At admission & $2(1-3)$ & $1(0-2)$ & $2(1-3)$ & $<0.001$ \\
\hline At $24 \mathrm{~h}$ & $2(1-3)$ & $2(1-3)$ & $2(1-3)$ & 0.006 \\
\hline Time from onset to admission $<24 \mathrm{~h}, \mathrm{n}(\%)$ & $2472(52.9)$ & $97(57.7)$ & $2375(52.8)$ & 0.20 \\
\hline Neurological deterioration, n (\%) & 166 (3.6) & $19(11.3)$ & $147(3.3)$ & $<0.001$ \\
\hline TOAST subtype, $\mathrm{n}(\%)$ & & & & $<0.001$ \\
\hline Large-artery atherosclerosis & $1951(41.8)$ & $66(39.3)$ & $1855(41.9)$ & \\
\hline Small-artery occlusion & $1066(22.8)$ & $19(11.3)$ & $1047(23.3)$ & \\
\hline Cardioembolism & $131(2.8)$ & $15(8.9)$ & $116(2.6)$ & \\
\hline Other & $176(3.8)$ & $5(3.0)$ & $171(3.8)$ & \\
\hline
\end{tabular}

IQR interquartile range, BMI body mass index, NIHSS National Institutes of Health Stroke Scale, TOAST Trial of Org 10172 in Acute Stroke Treatment

\begin{tabular}{|c|c|c|c|c|c|c|}
\hline & \multicolumn{2}{|c|}{ stroke recurrence } & \multicolumn{2}{|c|}{ stroke disability } & \multicolumn{2}{|c|}{ death } \\
\hline & $O R(95 \times C 1)$ & & $O R(95 \times C 1)$ & & $O R(95 \times C 1)$ & \\
\hline Age, $y$ & $1.00(0.99-1.01)$ & a & $1.05(1.04-1.06)$ & - & $1.03(1.01-1.05)$ & 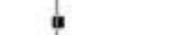 \\
\hline Female & $0.86(0.67-1.11)$ & $*$ & $1.10(0.87-1.40)$ & - & $1.20(0.79-1.83)$ & -- \\
\hline Hypertension & $1.33(1.02-1,72)$ & - & $1.12(0.88-1.43)$ & $\Rightarrow$ & $0.79(0.53-1.16)$ & 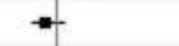 \\
\hline Diabetes mellitus & $1.28(1.02-1.60)$ & - & $1.98(1.61-2.45)$ & $\rightarrow-$ & $0.90(0.61-1.34)$ & 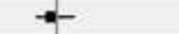 \\
\hline Dyslipidemia & $1.14(0.85-1.54)$ & -- & $0.89(0.65 .1 .23)$ & - & $0.87(0.50-1.53)$ & -- \\
\hline Atrial fibrillation & $2.02(1.41-2.90)$ & $\longrightarrow$ & $1.52(1.05-2.19)$ & $\rightarrow-$ & $1.88(1.10-3.21)$ & $\longrightarrow-$ \\
\hline Coronary heart disease & $1.37(1.03-1.81)$ & $\rightarrow-$ & $0.93(0.70-1.24)$ & - & $1.55(1.00-2.39)$ & $\rightarrow$ \\
\hline Previous stroke & $1.58(1.28-1.96)$ & $\rightarrow-$ & $1.39(1.13-1.71)$ & $\rightarrow$ & $1.40(0.98-2.00)$ & $\rightarrow-$ \\
\hline Current or previous smoking & $0.91(0.71-1.17)$ & - & $0.95(0.74-1.22)$ & + & $1.14(0.75-1.75)$ & $\rightarrow-$ \\
\hline Moderate or heavy alcohol & $1.15(0.81-1.64)$ & 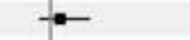 & $0.76(0.49-1.19)$ & $*$ & $0.71(0.34-1.51)$ & - \\
\hline BMI at admission, $\mathrm{kg} / \mathrm{m} 2$ & $1.00(0.97-1.03)$ & a & $1.00(0.97-1.03)$ & $n$ & $1.00(0.96-1.05)$ & " \\
\hline \multirow[t]{2}{*}{ Time from onset to admission $<24 \mathrm{~h}$} & $1.22(0.99-1.51)$ & - & $1.42(1.16-1.75)$ & 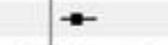 & $1.28(0.90-1.83)$ & - \\
\hline & & $\begin{array}{lll}1 & 1 & 1 \\
0.5 & 1.5 & 2.5\end{array}$ & & $\begin{array}{lll}1 & 1 & 1 \\
0.5 & 1.5 & 2.5\end{array}$ & & $\begin{array}{lll}1 & 1 & 1 \\
0.5 & 1.5 & 2.5\end{array}$ \\
\hline $\begin{array}{l}\text { Fig. } 2 \text { The adjusted ORs for stro } \\
\text { Rankin Scale > =3.OR denotes O } \\
\text { mellitus, dyslipidemia, atrial fibri } \\
\text { admission, and admission withir }\end{array}$ & $\begin{array}{l}\text { rence, disabilit } \\
\text {; Cl, Confider } \\
\text { oronary heart }\end{array}$ & $\begin{array}{l}\text { ind death at } 3 \text { n } \\
\text { Internal; BMI, Bc } \\
\text { ease, previous st }\end{array}$ & $\begin{array}{l}\text { nths after strok } \\
\text { y Mass Index. A } \\
\text { ke, current or }\end{array}$ & $\begin{array}{l}\text { onset. Stroke c } \\
\text { usted for age, } \\
\text { vious smoking }\end{array}$ & $\begin{array}{l}\text { lity was define } \\
\text { der, hypertensi } \\
\text { derate or hea }\end{array}$ & $\begin{array}{l}\text { as modified } \\
\text { n, diabetes }\end{array}$ \\
\hline
\end{tabular}


smaller community hospitals. Second, unavoidable delays before the inclusion of patients in the study led to the underestimation of the recurrent stroke risk and poor functional outcomes. The reason was that a portion of patients with minor stroke prior to study enrollment were not categorized into the group of minor stroke due to recurrent stroke or worsening of their presenting events. Third, it would be helpful if the abnormality on the imaging metric could be taken into as part of multivariate analysis for neurological deterioration. However, the detailed information about imaging was unavailable and the analysis couldn't be performed. Furthermore, as we mainly focus on the impact of risk factors before admission on outcomes, the other potentially significant factors including treatments and therapies variables during hospitalization and at discharge were not included in the analysis.

\section{Conclusions}

Our study indicated the short-term risk of early recurrent stroke and poor functional outcome in Chinese patients with a minor stroke was substantial. Therefore, patients with a minor stroke should be given expeditious assessment and urgent aggressive intervention.

\section{Abbreviations}

BMI: body mass index; Cl: confidence internals; CNSR: China National Stroke Registry; IQR: interquartile range; mRS: modified Rankin Scale; NIHSS: National Institutes of Health Stroke Scale; OR: odds ratios; SD: standard deviation; SSS-TOAST: Stop Stroke Study Trial of Org 10172 in Acute Stroke Treatment; TIA: transient ischemic attack.

\section{Competing interests}

The authors declare that they have no competing interests.

\section{Authors' contributions}

YiW and YoW planned and designed the study. XW, XZ, CW, LL, HZ, YC contributed to the acquisition and interpretation of data. LW, AW and XW analyzed the data. LW and AW were primarily responsible for writing the paper. YC and YiW revised the manuscript for important intellectual content. All authors read and approved the final manuscript.

\section{Acknowledgements}

We thank all participating hospitals, colleagues, nurses, imaging and laboratory technicians. A full list of the CNSR investigators are available at: http://onlinelibrary.wiley.com/doi/10.1111/j.1747-4949.2011.00584.x/suppinfo.

\section{Author details \\ ${ }^{1}$ Graduate School, North China University of Science and Technology, Tangshan, China. ${ }^{2}$ Department of Neurology, Beijing Tiantan Hospital, Capital Medical University, Beijing, China. ${ }^{3}$ China National Clinical Research Center for Neurological Diseases, Beijing, China. ${ }^{4}$ Center of Stroke, Beijing Institute for Brain Disorders, Beijing, China. ${ }^{5}$ Beijing Key Laboratory of Translational Medicine for Cerebrovascular Disease, Beijing, China. ${ }^{6}$ Department of Epidemiology and Health Statistics, School of Public Health, Capital Medical University, Beijing, China. ${ }^{7}$ Department of Neurology, Tangshan Gongren Hospital, Tangshan, China.}

Received: 18 August 2015 Accepted: 25 November 2015 Published online: 09 December 2015

\section{References}

1. Chen Z. The third national survey on the cause of death. Beijing, China: Peking Union Medical University Press; 2008.
2. Liu M, Wu B, Wang WZ, Lee LM, Zhang SH, Kong LZ. Stroke in China: epidemiology, prevention, and management strategies. Lancet Neurol. 2007;6(5):456-64. doi:10.1016/S1474-4422(07)70004-2.

3. Zhao D, Liu J, Wang W, Zeng Z, Cheng J, Liu J, et al. Epidemiological transition of stroke in China: twenty-one-year observational study from the Sino-MONICA-Beijing Project. Stroke. 2008;39(6):1668-74. doi:10.1161/ STROKEAHA.107.502807.

4. Coutts SB, Modi J, Patel SK, Aram H, Demchuk AM, Goyal M, et al. What causes disability after transient ischemic attack and minor stroke?: Results from the $C T$ and MRI in the Triage of TIA and minor Cerebrovascular Events to Identify High Risk Patients (CATCH) Study. Stroke. 2012;43(11):3018-22. doi:10.1161/STROKEAHA.112.665141.

5. Smith EE, Abdullah AR, Petkovska I, Rosenthal E, Koroshetz WJ, Schwamm $\mathrm{LH}$. Poor outcomes in patients who do not receive intravenous tissue plasminogen activator because of mild or improving ischemic stroke. Stroke. 2005;36(11):2497-9. doi:10.1161/01.STR.0000185798.78817.f3.

6. Barber PA, Zhang J, Demchuk AM, Hill MD, Buchan AM. Why are stroke patients excluded from TPA therapy? An analysis of patient eligibility. Neurology. 2001;56(8):1015-20.

7. Coull AJ, Lovett JK, Rothwell PM, Oxford VS. Population based study of early risk of stroke after transient ischaemic attack or minor stroke: implications for public education and organisation of services. BMJ. 2004;328(7435):326. doi:10.1136/bmj.37991.635266.44

8. Smith EE, Fonarow GC, Reeves MJ, Cox M, Olson DM, Hernandez AF, et al. Outcomes in mild or rapidly improving stroke not treated with intravenous recombinant tissue-type plasminogen activator: findings from get with the guidelines-stroke. Stroke. 2011;42(11):3110-5. doi:10.1161/STROKEAHA.111. 613208.

9. Nedeltchev K, Schwegler B, Haefeli T, Brekenfeld C, Gralla J, Fischer U, et al. Outcome of stroke with mild or rapidly improving symptoms. Stroke. 2007; 38(9):2531-5. doi:10.1161/STROKEAHA.107.482554.

10. Johnston SC, Gress DR, Browner WS, Sidney S. Short-term prognosis after emergency department diagnosis of TIA. Jama. 2000;284(22):2901-6.

11. Hill MD, Yiannakoulias N, Jeerakathil T, Tu JV, Svenson LW, Schopflocher DP. The high risk of stroke immediately after transient ischemic attack: a population-based study. Neurology. 2004;62(11):2015-20.

12. Lovett JK, Dennis MS, Sandercock PA, Bamford J, Warlow CP, Rothwell PM. Very early risk of stroke after a first transient ischemic attack. Stroke. 2003; 34(8):e138-40. doi:10.1161/01.STR.0000080935.01264.91.

13. von Weitzel-Mudersbach P, Andersen G, Hundborg HH, Johnsen SP. Transient ischemic attack and minor stroke are the most common manifestations of acute cerebrovascular disease: a prospective, population-based study-the Aarhus TIA study. Neuroepidemiology. 2013:40(1):50-5. doi:10.1159/000341696.

14. Wang Y, Cui L, Ji X, Dong Q, Zeng J, Wang Y, et al. The China Nationa Stroke Registry for patients with acute cerebrovascular events: design, rationale, and baseline patient characteristics. Int J Stroke. 2011;6(4):355-61. doi:10.1111/j.1747-4949.2011.00584.x.

15. Wang $Y$, Liao X, Zhao X, Wang DZ, Wang C, Nguyen-Huynh MN, et al. Using recombinant tissue plasminogen activator to treat acute ischemic stroke in China: analysis of the results from the Chinese National Stroke Registry (CNSR). Stroke. 2011;42(6):1658-64. doi:10.1161/STROKEAHA.110.604249.

16. Stroke-1989. Recommendations on stroke prevention, diagnosis, and therapy Report of the WHO Task Force on Stroke and other Cerebrovascular Disorders. Stroke; a journal of cerebral circulation. 1989;20(10):1407-31

17. Goldstein LB, Bertels C, Davis JN. Interrater reliability of the NIH stroke scale. Arch Neurol. 1989;46(6):660-2.

18. Fischer U, Baumgartner A, Arnold M, Nedeltchev K, Gralla J, De Marchis GM, et al. What is a minor stroke? Stroke. 2010;41(4):661-6. doi:10.1161/ STROKEAHA.109.572883.

19. Cappellari M, Bovi P, Moretto G, Zini A, Nencini P, Sessa M, et al. The THRombolysis and STatins (THRaST) study. Neurology. 2013;80(7):655-61. doi:10.1212/WNL.0b013e318281cc83.

20. Ay H, Furie KL, Singhal A, Smith WS, Sorensen AG, Koroshetz WJ. An evidence-based causative classification system for acute ischemic stroke. Ann Neurol. 2005;58(5):688-97. doi:10.1002/ana.20617.

21. Ois A, Gomis M, Rodriguez-Campello A, Cuadrado-Godia E, JimenezConde J, Pont-Sunyer $C$, et al. Factors associated with a high risk of recurrence in patients with transient ischemic attack or minor stroke. Stroke. 2008;39(6):1717-21. doi:10.1161/STROKEAHA.107.505438. 
22. Li SY, Zhao XQ, Wang CX, Liu LP, Liu GF, Wang YL, et al. One-year clinical prediction in Chinese ischemic stroke patients using the CHADS2 and CHA2DS2-VASC scores: the China National Stroke Registry. CNS Neurosci Ther. 2012;18(12):988-93. doi:10.1111/cns.12021.

23. Amarenco P, Lavallee PC, Labreuche J, Ducrocq G, Juliard JM, Feldman L, et al. Coronary artery disease and risk of major vascular events after cerebral infarction. Stroke. 2013;44(6):1505-11. doi:10.1161/STROKEAHA.111.000142.

24. Amarenco P, Lavallee PC, Labreuche J, Ducrocq G, Juliard JM, Feldman L, et al. Prevalence of coronary atherosclerosis in patients with cerebral infarction. Stroke. 2011;42(1):22-9. doi:10.1161/STROKEAHA.110.584086.

25. Expert Panel on Detection E, Treatment of High Blood Cholesterol in A. Executive summary of the third report of the National Cholesterol Education Program (NCEP) Expert Panel on Detection, Evaluation, and Treatment of High Blood Cholesterol In Adults (Adult Treatment Panel III). Jama. 2001;285(19):2486-97.

26. Mackintosh JE, Murtagh MJ, Rodgers $H$, Thomson RG, Ford GA, White M. Why people do, or do not, immediately contact emergency medical services following the onset of acute stroke: qualitative interview study. PLoS ONE. 2012;7(10):e46124. doi:10.1371/journal.pone.0046124.

Submit your next manuscript to BioMed Central and we will help you at every step:

- We accept pre-submission inquiries

- Our selector tool helps you to find the most relevant journal

- We provide round the clock customer support

- Convenient online submission

- Thorough peer review

- Inclusion in PubMed and all major indexing services

- Maximum visibility for your research

Submit your manuscript at www.biomedcentral.com/submit
() BioMed Central 